\section{Evaluations about \\ the physico-chemical stability of docetaxel and irinotecan pre-diluted and diluted solutions: pharmaco-economic perspectives}

Mariarita Laforgia, ${ }^{1}$ Anna Elisa Quatrale, ${ }^{2}$ Nicola A. Colabufo, ${ }^{3}$ Amalia Azzariti, ${ }^{2}$ Angelo Paradiso, ${ }^{2}$ Patrizia Nardulli ${ }^{1}$

1U.Ma.C.A. - Area di Farmacia, Istituto Tumori Giovanni Paolo II, Bari;

'Laboratorio di Farmacologia Clinica e

Pre-clinica, Istituto Tumori Giovanni

Paolo II, Bari; ${ }^{3}$ Dipartimento FarmacoChimico, Università degli Studi di Bari, Italy

\section{Abstract}

Several clinically used anticancer drugs are well-known as far as their pharmacologic properties are concerned, but scarcely ever the interest towards their physico-chemical characteristics in solution led to practical acknowledgement in their management. Thanks to the Units for Centralized Anticancer Drug Handling, the importance to evaluate the concentration of saturation (physical stability) or the possible transformations undergone by a drug in solution (chemical stability) has become the starting point for avoiding useless wasting drugs and economic resources. By HPLC experiments we have demonstrated that the solutions of two drugs, docetaxel and irinotecan, are particularly stable at different concentrations and times of analyses in our experimental conditions. The best mobile phase for docetaxel was water/methanol/acetonitrile in 42/32/26 volumetric ratio: for halving concentrations (0.72-0.36-0.18-0.09 $\mathrm{mg} / \mathrm{mL}$ ) in $\mathrm{NaCl} 0.9 \%$, the highest value gave a six-day and the three lower concentrations a fourteen-day stability, when storage occurred at room temperature and light protected. Elution of irinotecan was possible through an analysis in mobile phase gradient: at $\mathrm{t}_{0}$ a $20 \%$ ammonium acetate $10 \mathrm{mM}$ and $80 \%$ methano mixture, and after $5 \mathrm{~min}$, a $80 \%$ ammonium acetate $10 \mathrm{mM}$ and $20 \%$ methanol mixture. The physico-chemical stability was showed for five days, for any concentration of analysis when storage occurred at $2-8^{\circ} \mathrm{C}$ and light protected.

\section{Introduction}

Novel anticancer chemotherapy is charac- terized by a large arsenal of drugs, having very different chemical structures and different mechanisms of action.

Though never scientifically proved, the risk related to handling such molecules is something much debated and represents one of the starting points for the necessity of a right drug management. ${ }^{1,2}$ In this perspective, the exclusive handling management of chemotherapeutic drugs has been attributed to the hospital pharmacist within the Units for Centralized Anticancer drug Handling, granting not only the suitable competence, but also the best quality of the final product to oncological patients.

The quality and efficacy of anticancer drugs infusional solutions are linked to their physico-chemical stability as a function of different experimental conditions and parameters. Drug solutions are considered chemically and physically stable if the concentration is never under $95 \%$ of the starting value at different and established time intervals. ${ }^{3}$ Having either an organic or an organo-metallic chemical structure, these drugs are endowed with an inner physical and chemical instability, in solution above all, which is responsible of unrequested products, deriving from the gradual degradation of the parent molecule. Sun- or artificial light, humidity, solvents and excipients, oxygen and oxidative agents, temperature and final container materials could interact with the drug, provoking either its cleavage or its transformation or rearrangement in substances displaying severe toxicity. ${ }^{4-7}$ It should be common goal for all hospital pharmacists involved in handling and preparing oncological galenics to evaluate, with the help of proper technologies and expertise, the physico-chemical stability of every handled drug to the advantage of oncological patients. These data can directly help the pharmacist to employ already reconstituted solutions of the drug as multi-dose mother solutions for reasonably longer times, to anticipate the preparation or to destine a galenic product, prepared to a patient who cannot receive chemotherapy anymore, to another patient. Moreover, these options could benefit the economy of the hospital in sparing and destining economic resources to other needs, given the very high costs of some of commonly used antiblastic drugs. The choice of the drugs which underwent our analyses was carried out taking into account economic burden for the hospital, the frequency of prescription, and literature data which sometimes strongly contrast with the producer's official data.

The aim of present paper is to test through inverse phase HPLC analyses in order to verify the physico-chemical stability of docetaxel and irinotecan, two antiblastic drugs mainly employed in the chemotherapy of locally advanced or metastatic breast and colon can-
Correspondence: Amalia Azzariti, Clinical and Preclinical Pharmacology Laboratory, Istituto Tumori Giovanni Paolo II, viale 0. Flacco 65, 70125 Bari, Italy. Tel. +39.080.555.5986 E-mail: a.azzariti@oncologico.bari.it

Key words: docetaxel, irinotecan, physical-chemical stability, HPLC, precipitation.

Contributions: ML, drafted the manuscript; $\mathrm{AEQ}$ performed the experimental analysis of drugs stability; NAC, participated at the analysis of HPLC data and revised the manuscript; AA, conceived the study, coordinated the experimental design of the study, analyzed the data and revised the manuscript; AP, revised the manuscript; PN, revised the manuscript.

Conflict of interests: the authors declare no potential conflict of interests.

Received for publication: 11 March 2013.

Revision received: 25 June 2013.

Accepted for publication: 17 July 2013.

This work is licensed under a Creative Commons Attribution NonCommercial 3.0 License (CC BYNC 3.0).

(OC) Copyright M. Laforgia et al., 2013

Licensee PAGEPress, Italy

Drugs and Therapy Studies 2013; 3:e6

doi:10.4081/dts.2013.e6

cer, respectively. ${ }^{8-10}$ These drugs show quite high economic impact, and low stability according to the producers' warnings, although these details could be not supported by their structure. Our investigation started from the evidence that paclitaxel displayed chemical stability for 14 days in diluted and 27 days in mother solutions. Consequently it was investigated if the former reported to be stable only for 8 hours in pre-diluted and for 4 hours in diluted solutions, could be adjusted in terms of stability to reference drug.

\section{Materials and Methods}

All tests were performed by using the commercially available Taxotere ${ }^{\circledR}$ (Sanofi Aventis) and Campto ${ }^{\circledR} \quad$ (Pfizer) formulation injection concentrates, by means of inverse phase HPLC analyses (9010 Varian instrument, endowed with a C18 column $(250 \times 4.6 \mathrm{~mm} ; 5 \mu \mathrm{m})$ as stationary phase and UV detector). The stability of the docetaxel premix solution was also tested by ESI+/MS analysis. Determinations were performed with an Agilent 1100 Series LCMSD trap System VL workstation (HP6890-5973 MSD mass spectrometer). Each vial of Taxotere 80 mg was reconstituted with a $13 \%$ hydroalcoholic 
solution, supplied as diluting medium by the producer, to obtain a $10 \mathrm{mg} / \mathrm{mL}$ premix solution. The need of such a diluting agent is linked to the peculiar formulation of Taxotere injection concentrate with tween 80 ; it works as an emulsifying agent for a very lipophilic molecule, docetaxel, which is destined to intravenous administration in $0.9 \%$ sodium chloride aqueous solution. The premix solutions were diluted with saline solution to the most commonly prescribed concentrations and submitted to analysis in different experimental conditions of light and temperature. The mobile phase for the analysis was water/methanol/acetonitrile in $42 / 32 / 26$ volumetric ratio with a $1 \mathrm{~mL} / \mathrm{min}$ flow. The UV detector was set at $232 \mathrm{~nm}$, because docetaxel (but not tween 80 ) absorbs this wavelenghted-light. After elaborating a calibration curve reporting peak areas versus standard concentrations of drug for a $10 \mu \mathrm{L}$ fixed volume of tested solution, it was possible to evaluate the variations in drug concentration, by admitting a $10 \%$ error deriving from successive dilutions. The premix solutions of Campto $(20 \mathrm{mg} / \mathrm{mL}$ ) could be tested without prior reconstitution, simply after dilution in saline medium and submitted to the same starting procedures of Taxotere. Elution of the molecule was possible through an analysis in mobile phase gradient: at $\mathrm{t}_{0}$ a $20 \%$ ammonium acetate $10 \mathrm{mM}$ and $80 \%$ methanol mobile phase was used, then at $\mathrm{t}=5$ min, a $80 \%$ ammonium acetate $10 \mathrm{mM}$ and $20 \%$ methanol substituted the former. The fixed flow was $0.35 \mathrm{~mL} / \mathrm{min}$ and the UV detector was set at $380 \mathrm{~nm}$. The analyses were performed to test the stability of both the diluted solutions for administration, and the mother solutions of the two drugs, in order to understand if open vials, stored at controlled conditions, can be spared for the preparations in the following days.

\section{Sample preparation}

In the case of docetaxel, the $10 \mathrm{mg} / \mathrm{mL}$ premix solution was stored air- and light protected at different conditions of temperature $\left(25^{\circ} \mathrm{C}\right.$ and $\left.2-8^{\circ} \mathrm{C}\right)$, before further dilution with $0.9 \%$ sodium chloride medium to halving concentrations (0.72-0.36-0.18-0.09 $\mathrm{mg} / \mathrm{mL})$ in polyethylene containers. These samples (10 $\mu \mathrm{L}$ ) were then examined via HPLC analyses for reasonably long time intervals, or until the chromatographic peak area was changed with respect to its starting value. The same analytical procedures were used for both irinotecan mother solution at $20 \mathrm{mg} / \mathrm{mL}$ concentration and its diluted solutions (0.804-0.402-0.201 $\mathrm{mg} / \mathrm{mL}$ ) in $0.9 \% \mathrm{NaCl}$ polyethylene containers when storage occurred at $4^{\circ} \mathrm{C}$ and protected from light.

Each sample has been prepared and tested three times.

\section{Results and Discussion}

\section{Docetaxel solutions}

The linearity of the method was validated through the elaboration of a standard curve, reporting chromatographic peak areas as a function of standard concentrations of the drug in the clinically useful range of 0.09-0.72 $\mathrm{mg} / \mathrm{mL}$. The curve, deriving from a quadruple collecting data and repeated three times for each series of analysis, presents a medium weighted $r^{2}=0.999838$, confirming an accurate analysis.

The premix solution, stored in its original vial at room temperature or under refrigeration, air and light protected or not, and extemporary diluted for each analysis, was physically and chemically stable for 4 weeks at least. There is neither colour changing nor precipitation processes, nor reduction of the peak area during the whole analysis, so that the drug concentration in solution always remains near $100 \%$ of the starting value. The chromatographic profile with a retention time of $c a .4 .3$ minutes is reported in Figure 1A. In spite of the independence of stability from tempera- ture, it is convenient to store the vial of premix docetaxel concentrate at room temperature, because refrigeration provokes an increase of viscosity, which is responsible for a stressed difficulty in handling the solution. The stability of the solutions of docetaxel at the concentrations of administration, stored in polyethylene eppendorf was confirmed for 14 days at the three lower concentrations (Table 1).

The accuracy of measurements is supported both by the halving peak areas as a function of halving concentration values, and by the reasonably constant value of peak area within the same concentration at different times of analysis. The range of variations respects a medium error of measure within $10 \%$, evidently due to the experimental error rising from successive dilutions.

In the case of the highest concentration $(0.72 \mathrm{mg} / \mathrm{mL})$ after seven days of storage, precipitation processes occurred (Table 2). Little uncoloured needles adhere to the container, in the same time the chromatographic peak area reduces under $90 \%$ of its starting value. A massive precipitation of the drug occurs in the following days and it is certain that low temperatures accelerates the first solid nucleus forma-

Table 1. Chromatographic analysis for halving concentrations of docetaxel.

\begin{tabular}{lcccc} 
Premix sol. & Dilution & Final concentration & Time from dilution & Peak area \\
\hline Day 0 & Day 2 & $0.72 \mathrm{mg} / \mathrm{mL}$ & 0 & 16,000 \\
Day 0 & Day 2 & $0.36 \mathrm{mg} / \mathrm{mL}$ & 0 & 8254 \\
\hline Day 0 & Day 2 & $0.18 \mathrm{mg} / \mathrm{mL}$ & 0 & 4258 \\
Day 0 & Day 2 & $0.09 \mathrm{mg} / \mathrm{mL}$ & 0 & 2121 \\
\hline Day 0 & Day 2 & $0.72 \mathrm{mg} / \mathrm{mL}$ & $1 \mathrm{~d}$ & 15,900 \\
Day 0 & Day 2 & $0.36 \mathrm{mg} / \mathrm{mL}$ & $1 \mathrm{~d}$ & 8097 \\
\hline Day 0 & Day 2 & $0.18 \mathrm{mg} / \mathrm{mL}$ & $1 \mathrm{~d}$ & 4161 \\
Day 0 & Day 2 & $0.09 \mathrm{mg} / \mathrm{mL}$ & $1 \mathrm{~d}$ & 2088 \\
\hline Day 0 & Day 2 & $0.72 \mathrm{mg} / \mathrm{mL}$ & $7 \mathrm{~d} *$ & 14,310 \\
Day 0 & Day 2 & $0.36 \mathrm{mg} / \mathrm{mL}$ & $7 \mathrm{~d}$ & 8541 \\
\hline Day 0 & Day 2 & $0.18 \mathrm{mg} / \mathrm{mL}$ & $7 \mathrm{~d}$ & 4318 \\
Day 0 & Day 2 & $0.09 \mathrm{mg} / \mathrm{mL}$ & $14 \mathrm{~d} *$ & 2159 \\
\hline Day 0 & Day 2 & $0.72 \mathrm{mg} / \mathrm{mL}$ & $14 \mathrm{~d}$ & 10,971 \\
Day 0 & Day 2 & $0.36 \mathrm{mg} / \mathrm{mL}$ & $14 \mathrm{~d}$ & 8546 \\
\hline Day 0 & Day 2 & $0.18 \mathrm{mg} / \mathrm{mL}$ & $14 \mathrm{~d}$ & 4247 \\
Day 0 & Day 2 & $0.09 \mathrm{mg} / \mathrm{mL}$ & & 2102 \\
\hline
\end{tabular}

*Presence of precipitate.

Table 2. Chromatographic analysis of a $0.72 \mathrm{mg} / \mathrm{mL}$ solution of docetaxel.

\begin{tabular}{lcccc} 
Premix sol. & Dilution & Final concentration & Time from dilution & Peak area \\
Day 0 & Day 16 & $0.72 \mathrm{mg} / \mathrm{mL}$ & 0 & 13,500 \\
Day 0 & Day 16 & $0.72 \mathrm{mg} / \mathrm{mL}$ & $1 \mathrm{~d}$ & 13,600 \\
\hline Day 0 & Day 16 & $0.72 \mathrm{mg} / \mathrm{mL}$ & $5 \mathrm{~d}$ & 13,400 \\
Day 0 & Day 16 & $0.72 \mathrm{mg} / \mathrm{mL}$ & $6 \mathrm{~d}$ & 12,400 \\
\hline Day 0 & Day 16 & $0.72 \mathrm{mg} / \mathrm{mL}$ & $7 \mathrm{~d}^{*}$ & 6035 \\
\hline *Presence of precipitate. & & &
\end{tabular}

[Drugs and Therapy Studies 2013; 3:e6]

[page 25] 
nomic earning deriving from re-utilizing drug mother solutions after the deadline suggested by producers, a simple comparison was made between real and hypothetic consumptions of Taxotere vials within a tree-month period, by considering oncologists' prescriptions in their value, accompanied by the precipitation process. It is likely that the precipitate consists in pure docetaxel, as no other parameters differ from the other analytical concentrations, but there is still no scientific evidences about it. The stability of the $10 \mathrm{mg} / \mathrm{mL}$ docetaxel premix solution was also tested by ESI+/MS analysis. Determinations were performed with an Agilent 1100 Series LCMSD trap System VL workstation (HP6890-5973 MSD mass spectrometer) within a period of three days. The spectra registered in the daily experiments showed significant $\mathrm{m} / \mathrm{z}$ peaks for the parent molecule, having comparable percentages of relative intensity. To support our findings, recent studies ${ }^{11,12}$ reported a much higher stability, for docetaxel solutions at any concentration value in similar experimental conditions (till 28 days).

\section{Irinotecan solutions}

The linearity of the method was validated through the elaboration of a standard curve, reporting chromatographic peak areas as a function of standard concentrations of the drug in the useful range of $0.804-0.201$ $\mathrm{mg} / \mathrm{mL}$. The curve presents a medium weighted $r^{2}=0.9998$. The analyzed solutions $(0.804$ $0.402-0.201 \mathrm{mg} / \mathrm{mL}$ ), stored at $4^{\circ} \mathrm{C}$ and light protected, were chemically and physically stable for at least 5 days. This result is in contrast with the producer's warnings according to which all drug solutions at any concentration are stable till 24 hours after dilution when stored at $4^{\circ} \mathrm{C}$. The chromatographic profile with a retention time of $c a .3$ minutes is reported in Figure 1B. Variations of the peak areas with respect to its starting value occurred in the error range of $10 \%$, which represents the experimental error consequent to successive dilutions of little quantities of drug in little volumes of solution (Table 3).

In conclusion, the physico-chemical stability of irinotecan solutions in our experimental conditions are much higher than the data officially reported by the producer. Longer times of analysis, useless to our intents, demonstrated a low tendency of the molecule to degradation. After 14 days, for any concentration of the drug solution, the peak area underwent a $c a .22 \%$ reduction, even if no empirical evidence (precipitate or colour variation) let us understand which chemical transformation may occur. Our results confirmed analogous studies on analogous molecules reported in literature, ${ }^{13}$ in which camptothecins showed a long chemical stability above all thanks to the lack of reactive chemical groups that can cause intramolecular or intermolecular rearrangements.

\section{Economic perspectives}

Much longer times for the storage of anticancer drug vials after extemporary drawings, translate into concrete perspectives in favour of the hospital economy.

In order to get an idea of the possible eco-

Table 3. Chromatographic analysis of halving concentration solutions of irinotecan.

\begin{tabular}{lcc} 
Final concentration & Time from dilution & Peak area \\
$0.805 \mathrm{mg} / \mathrm{mL}$ & 0 & 31,561 \\
$0.402 \mathrm{mg} / \mathrm{mL}$ & 0 & 16,354 \\
\hline $0.201 \mathrm{mg} / \mathrm{mL}$ & 0 & 8851 \\
$0.805 \mathrm{mg} / \mathrm{mL}$ & $1 \mathrm{~d}$ & 30,439 \\
\hline $0.402 \mathrm{mg} / \mathrm{mL}$ & $1 \mathrm{~d}$ & 16,349 \\
$0.201 \mathrm{mg} / \mathrm{mL}$ & $1 \mathrm{~d}$ & n.a. \\
\hline $0.805 \mathrm{mg} / \mathrm{mL}$ & $2 \mathrm{~d}$ & 29,832 \\
$0.402 \mathrm{mg} / \mathrm{mL}$ & $2 \mathrm{~d}$ & 15,942 \\
\hline $0.201 \mathrm{mg} / \mathrm{mL}$ & $2 \mathrm{~d}$ & 8025 \\
$0.805 \mathrm{mg} / \mathrm{mL}$ & $5 \mathrm{~d}$ & 29,536 \\
\hline $0.402 \mathrm{mg} / \mathrm{mL}$ & $5 \mathrm{~d}$ & 14,552 \\
$0.201 \mathrm{mg} / \mathrm{mL}$ & $5 \mathrm{~d}$ & 8157 \\
\hline
\end{tabular}
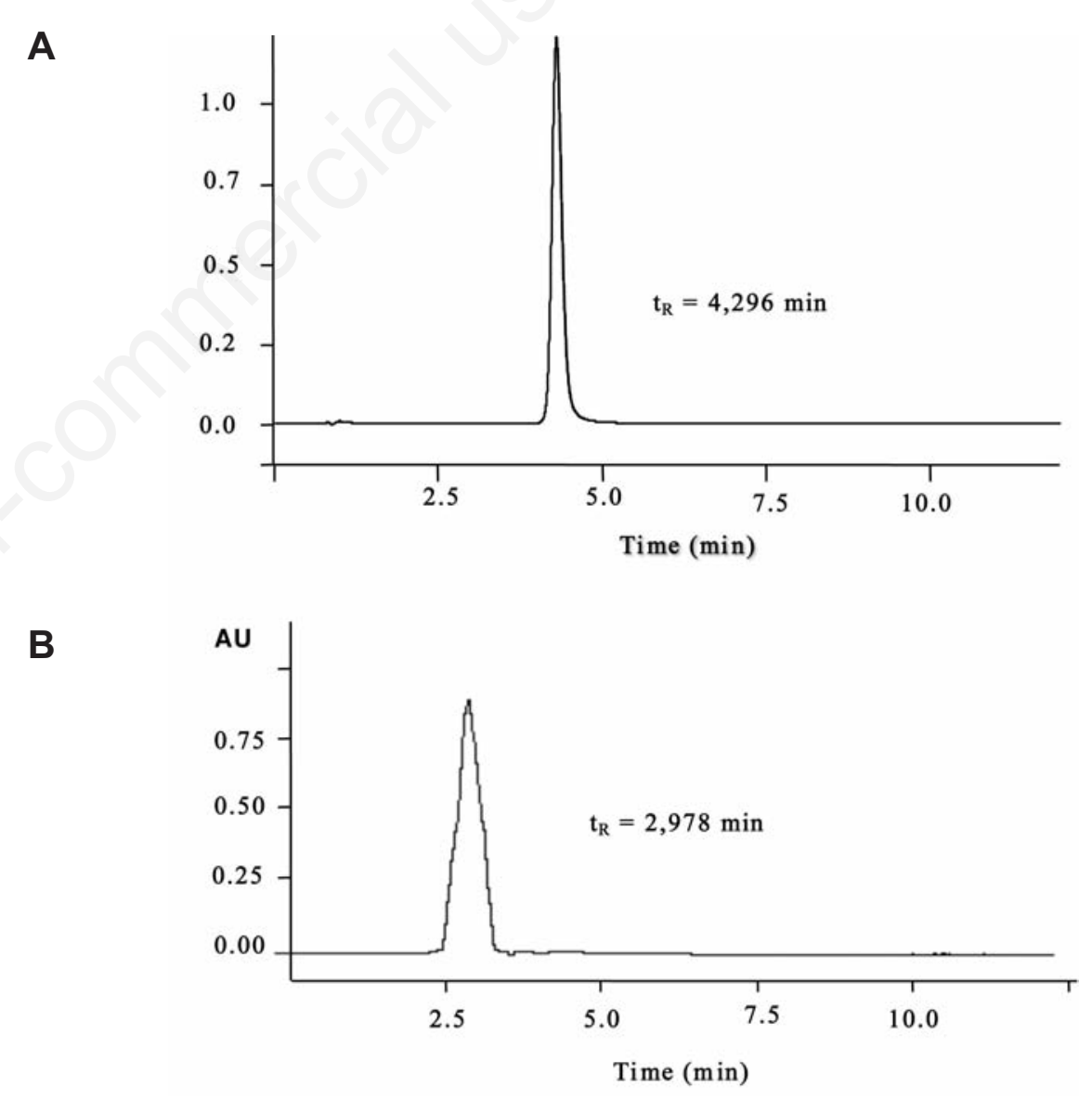

Figure 1. A) Chromatographic peak of docetaxel in solution. Inverse phase HPLC analysis. mobile phase: water/methanol/acetonitrile in 42/32/26 volumetric ratio; flow: 1 $\mathrm{mL} / \mathrm{min}$; $\lambda=232 \mathrm{~nm}$; Volume of analysis: $10 \mu \mathrm{L}$. B) Chromatographic peak of irinotecan in solution. Inverse phase HPLC analysis. Mobile phase gradient: t0 $20 \%$ ammonium acetate $10 \mathrm{mM}$ and $80 \%$ methanol; $\mathrm{t}=5 \mathrm{~min}, 80 \%$ ammonium acetate $10 \mathrm{mM}$ and $20 \%$ methanol; flow: $0.35 \mathrm{~mL} / \mathrm{min} ; \lambda=380 \mathrm{~nm}$; Volume of analysis: $10 \mu \mathrm{L}$. 
order of arriving at the pharmacy and admitting to store the vial of residual drug for the following working day in appropriate conditions. Within each month and day by day, the number of really consumed Taxotere vials, as collected in the management software of pharmacy, was compared to the hypothetical number of consumable vials, calculated on the base of daily prescribed doses and of sold off vials at the end of the about 20 monthly working days. Moreover, as Taxotere is commercially available in $20 \mathrm{mg}$ and $80 \mathrm{mg}$ vials, we have admitted that $80 \mathrm{mg}$ vials were more frequently used also for lower doses, because it is more convenient, in terms of safety during work and in terms of reconstitution medical devices costs, to handle one $80 \mathrm{mg}$ vial rather than three 20 $\mathrm{mg}$ vials to collect, for instance, a $60 \mathrm{mg}$ dose.

The difference between the real and the hypothetical number of Taxotere vials gives a monthly gain of about 21 Taxotere $80 \mathrm{mg}$ vials, that correspond to about $15 \%$ of plus usable drug. It is quite surprising that a mean quantity of one $80 \mathrm{mg}$ drug vial a day can be spared. This result springs from both the high frequency of docetaxel prescriptions and its wide range of doses $\left(30-100 \mathrm{mg} / \mathrm{m}^{2}\right)$, so that a residual drug vial is consumed within 24 hours at most and the frequent low doses can be easily recovered. As far as diluted solutions for administration are concerned, the possibility to anticipate galenic preparations could be translated into a minor economic burden for the hospital, thanks to the spared remuneration for pharmacists and operators out of their regular working time.

The gain in number of spared vials is even much higher if we consider that the single Unit for Centralized Anticancer Drug Handling is substituting a variable number of centres of preparation within a single hospital, each of which was likely to sell off the last drug vial of the working day.

On the basis of this data collection, the scientific impact of our experimental results could be closely linked to a concrete economic advantage for the hospital and to a better distribution of resources.

\section{Conclusions}

During the last five years, the shift from different centres of preparation within the same hospital to a single Unit for Centralized Anticancer Drug Handling gave rise to a system of quality and risk reduction, which consigns in the pharmacists' hands the responsibility mainly for the safety and quality of the patients' intravenous therapy, but also for the best management of the economic resources destined to drug purchase.

The experimental analyses via HPLC Inverse phase method on docetaxel and irinotecan prediluted and diluted solutions deserve a particular attention for different points of view.

In more general terms, HPLC analyses could be carried out, employing validate protocols, i) to restore drug fractions; ii) to collect a specific database in terms of time-dependently stability of each drug; iii) to perform before beginning pharmacological therapy, a random quality control on packaging of drug.

\section{References}

1. Cavallo D. Evaluation of genotoxic effects induced by exposure to antineoplastic drugs in lymphocytes and exfoliated buccal cells of oncology nurses and pharmacy employees. Mut Res 2005;587:45 51.

2. Acampora A. A case study: surface contamination of cyclophosphamide due to working practices and cleaning procedures in two Italian hospitals. Ann Occup Hyg 2005;49:611 8.

3. Connors KA, Amidon GL, Stella VJ. Chemical stability of pharmaceuticals. A handbook for pharmacists. 2nd ed. Hoboken: John Wiley \& Sons; 1986.

4. Mirkes PE. Cyclophosphamide teratogenesis: a review. Teratogenesis, Carcinogenesis and Mutagenesis 2005;5: 7588.

5. Weenen H, Osterop APRM., Van der Poort SEJM, et al. Analysis of doxorubicin, 4'epidoxorubicin, and their metabolites by liquid chromatography. J Pharm Sci 2006; 75:12014.

6. Beijnen JH, Holthuis JJM, Kerkdijk HG, et al. Degradation kinetics of etoposide in aqueous solution. Int J Pharm 1988;41: 16978.

7. Shetty BV, Schowen RL, Slavik M. Degradation of dacarbazine in aqueous solution. J Pharm Biomed Anal 1992;10: 67583.

8. Lam YWF, Chan CYJ, Kuhn JG. Review: pharmacokinetics and pharmacodynamics of the taxanes. J Oncol Pharm Pract 1997; 3:76 93.

9. Bissery MC. Preclinical pharmacology of docetaxel. Eur J Cancer 1995;31 Suppl 4: S1 S6.

10. Fischer DS, Knobf MT, Durivage HJ. Chemioterapia antitumorale. Milano: Elsevier-Masson; 1993.

11. Thiesen J, Krämer I. Physico-chemical stability of docetaxel premix solution and docetaxel infusion solutions in PVC bags and polyolefine containers. Pharm Wrld Sci 1999;21:137 41.

12. Mazzo DJ, Nguyen-Huu JJ, Pagniez S, Denis P. Compatibility of docetaxel and paclitaxel in intravenous solutions with polyvinyl chloride infusion materials. Am J Health Syst Pharm 1997;54:566 9.

13. Boyd G, Smyth JF, Jodrell DI, Cummings J. High-performance liquid chromatographic technique for the simultaneous determination of lactone and hydroxyl acid forms of camptothecin and SN-38 in tissue culture media and cancer cells. Anal Biochem 2001;297:15 24. 